8 - ORIGINAL ARTICLE

EXPERIMENTAL SURGICAL INFECTIONS

\title{
Scintigraphic imaging with technetium-99M-labelled ceftizoxime is a reliable technique for the diagnosis of deep sternal wound infection in rats $^{1}$
}

\author{
Paulo Henrique Nogueira Costa ${ }^{\mathrm{I}}$, Simone Odilia Fernandes Diniz ${ }^{\mathrm{II}}$, Valbert Nascimento Cardoso ${ }^{\mathrm{II}}$, Bernardo Tarabal ${ }^{\mathrm{II}}$, Isabella \\ Takenaka $^{\text {IV }}$, Otavio Braga ${ }^{\text {, Paula Vieira Teixeira Vidigal }}{ }^{\text {VI }}$, Claudio Leo Gelape ${ }^{\text {VII }}$, Ivana Duval Araujo ${ }^{\text {VII }}$
}

\author{
DOI: http://dx.doi.org/10.1590/S0102-865020150090000008
}

IMaster, Faculty of Medicine, Universidade Federal de Minas Gerais (UFMG), Belo Horizonte-MG, Brazil. Conception and design of the study; technical procedures; acquisition, analysis and interpretation of data; manuscript writing.

"PhD, Associate Professor, Faculty of Pharmacy, UFMG, Belo Horizonte-MG, Brazil. Acquisition and interpretation of data, critical revision.

IIIFellow Master degree, Faculty of Medicine, UFMG, Belo Horizonte-MG, Brazil. Technical procedures.

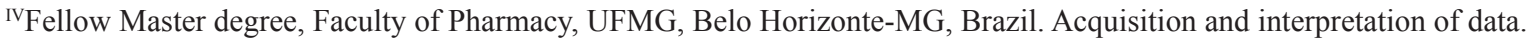

${ }^{\mathrm{v}} \mathrm{MD}$, Faculty of Medicine, UFMG, Belo Horizonte-MG, Brazil. Technical procedures.

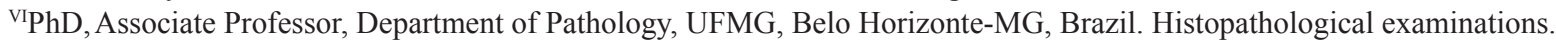

${ }^{\mathrm{V} I \mathrm{PhD}}$, Associate Professor, Department of Surgery, UFMG, Belo Horizonte-MG, Brazil. Conception and design of the study, technical procedures, analysis and interpretation of data, critical revision.

\section{ABSTRACT}

PURPOSE: To evaluate whether scintigraphy with technetium-99m-labeled ceftizoxime (99m $\mathrm{mc}-\mathrm{CFT})$ can differentiate mediastinitis from aseptic inflammation associated with sternotomy.

METHODS: Twenty female Wistar rats were randomly distributed into four groups: S (control) -partial upper median sternotomy with no treatment; SW (control) - sternotomy and treatment of sternal wounds with bone wax; SB - sternotomy and infection with Staphylococcus aureus; SWB - sternotomy with bone wax treatment and bacterial infection. Scintigraphy with ${ }^{99 \mathrm{~m} T c-C F T}$ was performed eight days after surgery and images were collected 210 and $360 \mathrm{~min}$ after infusion of the radiopharmaceutical.

RESULTS: No animals exhibited clinical signs of wound infection at the end of the experiment, although histological data verified acute inflammatory response in those experimentally infected with bacteria. Scintigraphic images revealed that tropism of ${ }^{99 \mathrm{~m} T c-C F T}$ to infected sternums was greater than to their non-infected counterparts. Mean counts of radioactivity in bacteria-infected sternal regions (SB and SWB) were significantly higher $(p=0.0007)$ than those of the respective controls ( $\mathrm{S}$ and $\mathrm{SW}$ ).

CONCLUSION: Scintigraphy with technetium-99m-labeled ceftizoxime is a method that can potentially detect infection post sternotomy and differentiate from aseptic inflammation in animals experimentally inoculated with S. aureus.

Key words: Wound Infection. Radionuclide Imaging. Sternotomy. Technetium. Rats. 


\section{Introduction}

Longitudinal median sternotomy is the most common surgical approach employed in cardiac procedures ${ }^{1}$ because it is readily performed, allows full exposure of the mediastinum, presents a low incidence of morbidity and mortality, and is well tolerated by patients in the postoperative period. However, despite the various advantages of the technique, serious complications, including life-threatening mediastinitis, may arise.

Mediastinitis is a deep sternal wound infection that is associated with sternal osteomyelitis, with or without involvement of the retrosternal space. Although the incidence of mediastinitis following median sternotomy is comparatively low, typically between 0.4 to $5 \% \%^{2}$, the frequency of mortality may attain $47 \%$ even when appropriate treatment is provided ${ }^{3}$. Moreover, the occurrence of mediastinitis exerts a negative impact on the ensuing survival of patients and on hospital costs ${ }^{4}$. Diagnosis of mediastinitis is frequently established belatedly because the initial symptoms are non-specific, and the sensitivity and specificity of laboratory and radiological methods of analysis are $\operatorname{low}^{5-7}$. The resulting delay in the commencement of treatment often results in poor prognosis for patients and reduces the chances of survival ${ }^{7}$.

In scintigraphy, the gamma radiation emitted by certain radioisotopes, typically attached to an appropriate marker compound, is captured by a gamma camera and processed to generate two-dimensional images. Technetium-99m (Tc99m), a natural decay product of molybdenum-99 (Mo-99), is a short-lived, gamma-emitting, metastable nuclear isomer of Tc-99. Chemically, Tc-99m is relatively reactive and, being a metal deficient in electrons, interacts mainly with functional groups capable of donating electrons. The isotope has excellent qualities for the acquisition of scintigraphic images which, combined with its availability and low cost of production, has led to its use in over $80 \%$ of examinations in nuclear medicine. Ceftizoxime is a third generation, beta-lactamase-stable semisynthetic cephalosporin that exhibits activity against a wide spectrum of aerobic and anaerobic Gram-positive and Gramnegative bacteria by binding to cell walls. The antibiotic possesses various functional groups that act as electron donors and are able to bind to Tc-99m. Diniz et al. ${ }^{8}$ have demonstrated the reliability of scintigraphic imaging with ${ }^{99 \mathrm{~m}}$ Tc-ceftizoxime for the differentiation of infectious and inflammatory foci using an osteomyelitis-induced animal model system.

In the present study, we have examined the hypothesis that mediastinitis can be diagnosed by scintigraphic imaging using a radiolabeled antibiotic probe. The aim of the investigation was to assess the effectiveness of ${ }^{99 \mathrm{~m}} \mathrm{Tc}$-ceftizoxime in the detection of subclinical DSWI using a murine model system.

\section{Methods}

Details of the project were submitted to and approved by the Ethics Committee in Animal Experimentation of the Universidade Federal de Minas Gerais (CETEA/UFMG, protocol no. 143/2011). The experiments were conducted in the Laboratory of Experimental Surgery of the Faculty of Medicine at UFMG. All of the procedures described were carried out in accordance with the guidelines issued by the Central Animal Facility of UFMG.

\section{Study population and experimental design}

The study population comprised 20 two-month old female Wistar rats (weight range 200-230 g) obtained from the Central Animal Facility of UFMG. The animals were housed in wire-mesh cages (maximum of 5 animals per cage) and maintained throughout the experimental period in a temperaturecontrolled room under a normal light cycle and with free access to water and food. The sample population was distributed randomly into four groups, namely, control group $\mathrm{S}(\mathrm{n}=3$; submitted to sternotomy), control group SW ( $\mathrm{n}=3$; submitted to sternotomy with application of bone wax), experimental group SB ( $\mathrm{n}=7$; submitted to sternotomy with application of bacterial inoculum), and experimental group SWB ( $\mathrm{n}=7$; submitted to sternotomy with application of bone wax plus bacterial inoculum).

\section{Preparation of bacterial inoculum}

Cultures of the multisusceptible Staphylococcus aureus strain ATCC6538-P were grown up on Antibiotic Agar no. 1 plates (Merck, Darmstadt, Germany) and bacterial colonies were suspended in sterile saline solution to a concentration of $1 \times 10^{9}$ colony forming units $(\mathrm{CFU}) / \mathrm{mL}$ as determined spectrophotometrically at $580 \mathrm{~nm}$. Subsequently, an aliquot (1 $\mathrm{mL}$ ) of the suspension was transferred to $9 \mathrm{~mL}$ of trypticase soy agar, homogenised and distributed in an $80 \mathrm{~mm}$ diameter Petri dish. Immediately prior to surgery, the gel layer was divided into squares $(5 \times 5 \mathrm{~mm})$, each of which was subdivided in two equal rectangles. The bacterial inoculum present in each rectangular segment was estimated to be $2.5 \times 10^{6} \mathrm{CFU}$ on a proportional area basis (area of Petri dish base $=\left[\pi / 4 \times(80)^{2}\right] \mathrm{mm}^{2}$; area of rectangle $=12.5 \mathrm{~mm}^{2}$; proportional ratio $\left.» 1 / 400\right)$. 


\section{Preparation of ${ }^{99 m}$ Tc-ceftizoxime}

The radiopharmaceutical was prepared according to the method of Diniz et al. ${ }^{9}$. Briefly, a non-commercial kit prepared by the Radioisotopes Laboratory of Faculty of Pharmacy at UFMG, containing lyophilized ceftizoxime $(2.5 \mathrm{mg})$ and the reducing agent sodium dithionite $(6.0 \mathrm{mg})$ was reconstituted with $1.0 \mathrm{~mL}$ of sodium pertechnetate $\left(\mathrm{Na}^{99 \mathrm{~m}} \mathrm{TcO}_{4} ; 444 \mathrm{MBq}\right)$ obtained by elution from a sterile Mo-99/Tc-99m generator (Instituto de Pesquisas Energéticas e Nucleares - IPEN, São Paulo-SP, Brasil) with sterile saline solution. The reaction mixture was heated to $100^{\circ} \mathrm{C}$ for $10 \mathrm{~min}$, cooled under running water for $5 \mathrm{~min}$, filtered through a cellulose ester membrane $(0.22 \mathrm{~mm})$ to remove radiochemical contaminants (mainly ${ }^{99} \mathrm{TcO}_{2}$ ) and collected under vacuum.

\section{Surgical procedure}

Surgeries were performed using standard aseptic techniques. The animal was anesthetized by intraperitoneal injection of a mixture of xylazine (5 mg/kg) and ketamine (40 mg/ $\mathrm{kg}$ ), the chest area was shaved, the surgical site was cleaned with $70 \%$ isopropyl alcohol and 2\% iodine solutions, iodine doesn't interfere with the uptake of the ${ }^{99 \mathrm{~m}} \mathrm{Tc}-\mathrm{CFT}$, and a sterile fenestrated towel was used to cover the sternum. The skin and presternal layers were incised with a scalpel and, following divulsion of the retrosternal space, partial upper median sternotomy was performed with straight sharp/sharp scissors. Bone wax (B. Braun, São Gonçalo-RJ, Brasil) was applied between the sternal halves of animals of the SW and SWB groups. The sternal halves were closed with Nylon 3-0 monofilament sutures, after which a gel segment containing bacterial inoculum was applied over the sternum of the SB and SWB animals. Finally, the panniculus carnosus and skin were closed with Nylon 3-0 monofilament sutures.

\section{Scintigraphic analysis}

Experimental animals were injected in the tail vein with approximately $0.15 \mathrm{~mL}$ of ${ }^{99 \mathrm{~m}} \mathrm{Tc}$-ceftizoxime solution $(1.8 \mathrm{MBq})$ eight days after surgery. At pre-established times (210 and 360 min) after administration of radiopharmaceutical, the animals were anesthetized with a mixture of xylazine $(7.5 \mathrm{mg} / \mathrm{kg})$ and ketamine $(60 \mathrm{mg} / \mathrm{kg})$ and placed in the supine position under a gamma-ray camera equipped with a low-energy collimator (Nuclide $^{\mathrm{TM}}$ TH 22, Mediso, Hungary). Static planar images (matrix of 256 x 256 pixels) were acquired over a $10 \mathrm{~min}$ period and the levels of radioactivity within the regions of interest (ROIs) around the sternums (target area; Figure 1) of control and experimental animals were evaluated during $10 \mathrm{~min}$ and expressed as number of counts.

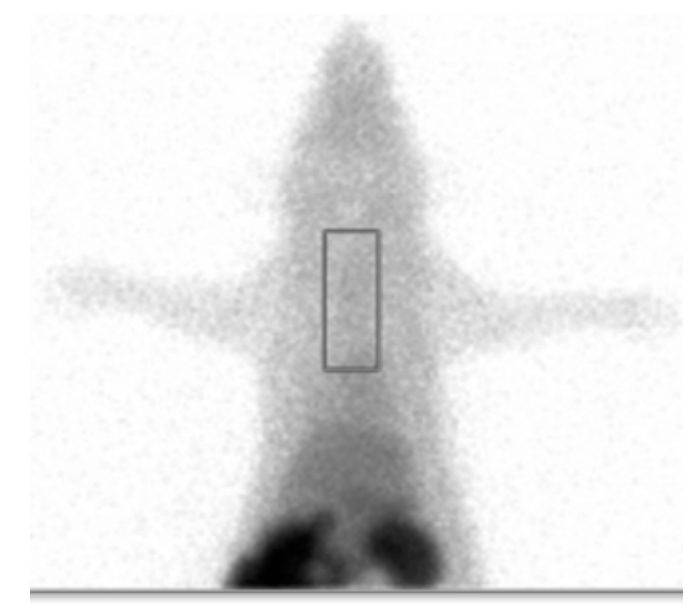

FIGURE 1 - Region of interest (target) around the sternum of an experimental rat delimited by a rectangle for the purposes of scintigraphy with ${ }^{99 \mathrm{~m}} \mathrm{Tc}$-ceftizoxime.

\section{Ex vivo radioactive counting and histopathological analysis of sternums}

After the gamma images had been obtained, the rats were euthanized by cervical dislocation and the sternums were surgically removed under aseptic conditions, weighed and the amounts of radioactivity taken up by the resected tissues measured using a Wallac 1470 Wizard Gamma Multi-well Counter (Perkin Elmer, São Paulo-SP, Brasil). Radioactive uptake was expressed as cpm/g of tissue.

Resected sternums were fixed in $10 \%$ buffered formalin and embedded in paraffin. Sections ( $5 \mu \mathrm{m}$ thick) were stained with hematoxylin and eosin and analyzed under an Olympus (Olympus Europe, Hamburg, Germany) model AX70 light microscope.

\section{Statistical analysis}

Statistical analyses were carried out with the aid of SPSS ${ }^{\circledR}$ statistics package for Windows, version 21.0 (IBM Corporation, Armonk, NY, USA). Results were expressed in the form mean \pm standard error. Analysis of continuous data was performed using repeated measures analysis of variance (ANOVA) and Fisher's least significant difference (LSD) test. Data relating to ex vivo radioactive counting were analyzed using the non-parametric Kruskal-Wallis test. Between-group comparisons were performed considering a level of significance of $95 \%(p<0.05)$. 


\section{Results}

Of the 20 rats initially selected for experimentation, one died immediately after sternotomy (SB group), probably as a result of pneumothorax. No animals showed any signs or symptoms of sternal wound infection during the experiment.

Inspection of the scintigraphic images indicated that the radioactive emissions from the sternum areas of rats decreased between 210 and 360 min after the injection of ${ }^{99 m}$ Tc-ceftizoxime, and that radiation intensity was stronger in the SB and SWB groups at 210 min compared with the other groups (Figure 2). These findings were verified by quantitative analyses, which revealed that the number of counts in the ROIs decreased significantly (ANOVA; $p=0.0001$ ) between 210 and $360 \mathrm{~min}$ after injection of the radiopharmaceutical. Although this result was expected because of the natural decay of ${ }^{99 \mathrm{~m}} \mathrm{Tc}$ with time, the percentage reductions in counts in the SB and SWB groups were significantly lower than those observed for the S and SW groups, indicating that the radiopharmaceutical was specifically fixed to the bacteria (Table 1). Moreover, the counts in the ROIs of SB and SWB animals were significantly (ANOVA; $p=0.0007$ ) higher than those of their control counterparts (groups S and SW, respectively) at both 210 and $360 \mathrm{~min}$ after injection of ${ }^{99 \mathrm{~m}} \mathrm{Tc}$-ceftizoxime. a)

S

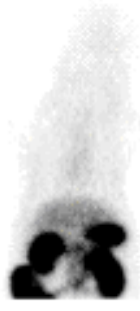

b)

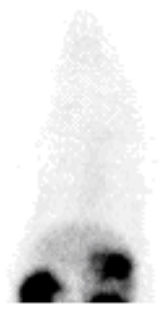

SW

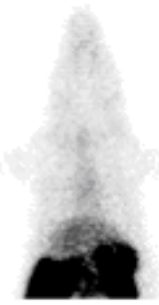

SB
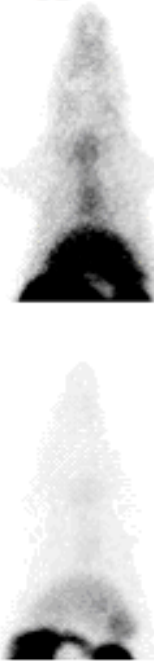

SWB
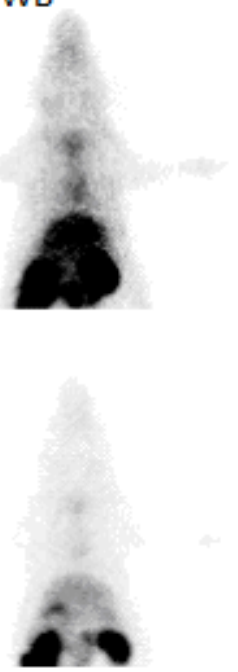

FIGURE 2 - Scintigraphic images showing the intensities of radioactivity in the target areas of control groups $\mathrm{S}$ (sternotomy) and SW (sternotomy and application of bone wax), and experimental groups SB (sternotomy and application of bacterial inoculum) and SWB (sternotomy and application of bone wax plus bacterial inoculum) at (a) 210 min and (b) 360 min after injection of ${ }^{99 \mathrm{~m}} \mathrm{Tc}-$ ceftizoxime.

TABLE 1 - Levels of radioactivity detected in the regions of interest (ROI) and resected sternums after injection of ${ }^{99 \mathrm{~m}}$ Tcceftizoxime in rats submitted to sternotomy.

\begin{tabular}{lcccc}
\hline \multirow{2}{*}{ Assay } & \multicolumn{5}{c}{ Level of radioactivity detected } \\
\cline { 2 - 5 } & Group S $(n=3)$ & Group SW $(n=3)$ & Group SB $(n=6)$ & Group SWB $(n=7)$ \\
\hline ROI - after 210 min & $7902.3 \pm 874.2^{\mathrm{A} 1}$ & $8708 \pm 1177.4^{\mathrm{A} 2}$ & $11495.5 \pm 2167.7^{\mathrm{B} 1}$ & $12258.2 \pm 1729^{\mathrm{B} 2}$ \\
ROI - after 360 min & $4920.6 \pm 562.9^{\mathrm{A} 1}$ & $6170.3 \pm 1419.3^{\mathrm{A} 2}$ & $7492.4 \pm 1403.5^{\mathrm{B} 1}$ & $8942.3 \pm 1378.3^{\mathrm{B} 2}$ \\
\hline \multicolumn{5}{c}{ Ex vivo assay (counts per g of tissue) } \\
\hline Resected sternums & $379.3 \pm 38.7 \times 10^{3 \mathrm{~A}}$ & $453.1 \pm 54.9 \times 10^{3 \mathrm{~A}}$ & $631.0 \pm 165.7 \times 10^{3 \mathrm{~B}}$ & $701.1 \pm 116.7 \times 10^{3 \mathrm{~B}}$ \\
\hline
\end{tabular}

Group S: submitted to sternotomy; group SW: submitted to sternotomy and application of bone wax; group SB: submitted to sternotomy and application of bacterial inoculum; group SWB: submitted to sternotomy and application of bone wax plus bacterial inoculum

Data represent mean values \pm standard error.

Regarding the in vivo assay, in each row, dissimilar upper-case superscript letters with similar numerical indexes indicate statistical differences (ANOVA; $\mathrm{p}<0.05$ ).

Regarding the ex vivo assay, dissimilar upper-case superscript letters indicate significant differences (Kruskal-Wallis; $\mathrm{p}<0.05)$. 
As shown in Table 2, the presence of bacteria in the surgical wounds was significantly associated with high levels of radioactivity in the ROIs (ANOVA; $p=0.0007$ ), while the application of bone wax had no influence on the intensity of radiation (ANOVA; $p=0.168$ ). These results indicated that the retention of ${ }^{99 m} \mathrm{Tc}$-ceftizoxime was significantly higher in the groups infected with bacteria (SB and SWB) in comparison with the non-infected groups ( $\mathrm{S}$ and $\mathrm{SW}$ ), and retention of the radiopharmaceutical was not affected by the presence of bone wax.

The ex vitro assays of resected sternums showed that groups SB and SWB retained significantly higher (Kruskal-Wallis; $\mathrm{p}<0.05$ ) amounts of radioactivity than the respective control groups S and SW (Table 2), indicating that the uptake of ${ }^{99 \mathrm{~m}} \mathrm{Tc}-$ ceftizoxime by tissue was increased in the presence of bacterial infection. Indeed, the relative numbers of counts per gram of tissue in the animal groups were as follows: $\mathrm{SB}=\mathrm{SWB}>\mathrm{S}=\mathrm{SW}$.

TABLE 2 - Influence of the investigated variables on the levels of radioactivity detected in the regions of interest in the groups of rats submitted to sternotomy.

\begin{tabular}{lcc}
\hline Source of variation & $F$ & $p$ \\
\hline Bone wax & 2.10 & 0.1683 \\
Bacteria inoculum & 17.94 & 0.0007 \\
Bone wax and bacteria inoculum & 0.01 & 0.9582 \\
Time & 260.17 & 0.0001 \\
Time and bacteria inoculum & 5.11 & 0.0391 \\
\hline
\end{tabular}

Histopathological analysis of sternum tissues revealed a high tropism of polymorphonuclear infiltrate towards the infected areas of the sternum (Figure 3). While the SB and SWB groups presented a severe suppurative inflammatory response, the $\mathrm{S}$ and SW groups presented only a mild non-suppurative inflammation.

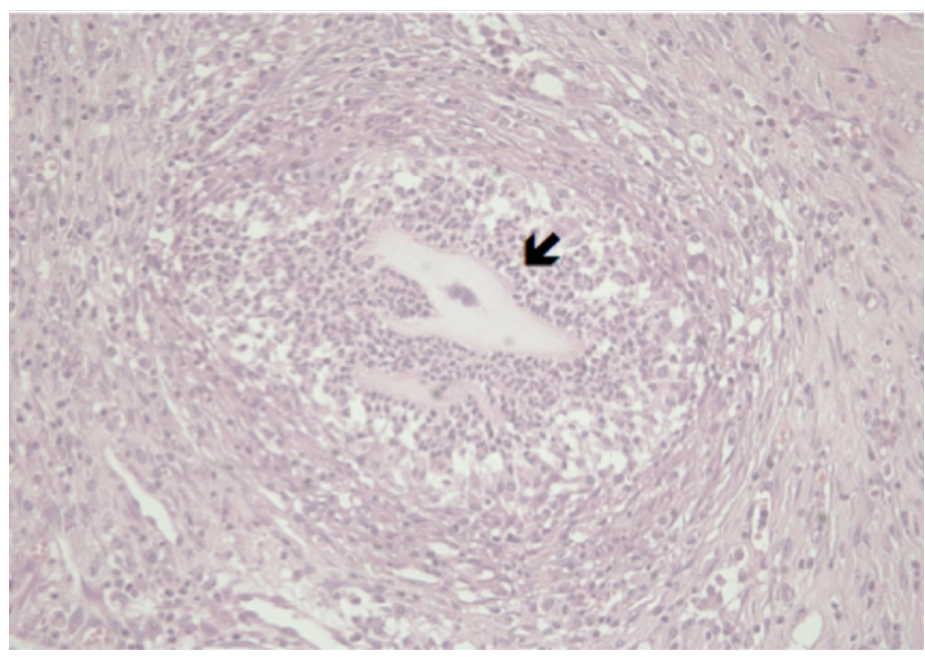

FIGURE 3 - Polymorphonuclear infiltrate (arrow) in a section of the sternum of a rat that had been submitted to sternotomy and application of bone wax plus bacterial inoculum (SWB group).

\section{Discussion}

The complications associated with the healing of sternal wounds are often severe and difficult to manage therapeutically, thus representing a significant challenge to cardiovascular surgeons. Mediastinitis is a complication that exhibits one of the highest rates of morbidity and mortality, even when appropriately treated, and is responsible for increased medical and hospital costs and for decreased life expectancy of the patient ${ }^{4}$. While superficial sternal wound infections can be clinically diagnosed very easily, the detection of deep wound infections involving sternal bones and/or retrosternal space is often more difficult. Therefore, the discrimination between superficial and deep wound infections, the diagnosis of subclinical deep wound infection in patients exhibiting no signs of superficial infection, and elimination of the possibility of infection in patients with sterile sternal dehiscence is extremely important because the treatment and prognosis for the three problems are very different.

Gamma scintigraphy is a non-invasive and highly sensitive technique that allows in vivo imaging of the distribution of gamma-emitting radiopharmaceuticals. Although non-specific radioactive agents accumulate in inflamed or infected tissues by virtue of increased blood flow, greater vascular permeability and the extravasation of proteins, their accuracy in the diagnosis of surgical site infections is low because the inflammatory response that is normally observed in the postoperative period distorts the results ${ }^{10}$. In contrast, specific radiopharmaceuticals interact exclusively with target sites as, for example, cephalosporin that binds specifically with the protein receptors present in bacteria cell walls.

The results presented herein demonstrate that ${ }^{99 \mathrm{~m}} \mathrm{Tc}-$ ceftizoxime scintigraphy can preferentially localize deep sternal wound infection in rats, even in the absence of clinical signs of infectious processes. As demonstrated by in vivo scintigraphy, the presence of bacteria in the ROIs was significantly associated with high levels of radioactivity at both evaluation times, namely, 210 and 360 min after injection. Ex vivo radioactive counting, which is considered the gold-standard in experimental studies, confirmed that radioactivity was significantly higher in the sternums of SB and SWB animals compared with those of S and SW animals. Furthermore, histopathological analysis of sternal tissues revealed that a suppurative inflammatory reaction occurred in the animals in the SB and SWB groups, while this phenomenon was not observed in the other groups. The present findings regarding the preferential localization of ${ }^{99 \mathrm{~m}} \mathrm{Tc}$-ceftizoxime in infected sternums are in accord with those of Diniz et al. ${ }^{8}$ who demonstrated a tropism of the radiopharmaceutical towards infectious foci located in tibias of rats with experimentally induced osteomyelitis. 
Bone wax, which comprises a mixture of beeswax and emollients such as paraffin, is often used to prevent bleeding from exposed spongy bone following median sternotomy. The wax is not absorbed by the body but, as for any implanted foreign material, may induce a number of side effects including acting as a niche for infections, thereby increasing susceptibility to mediastinitis ${ }^{11}$. Bone wax has been associated with intense inflammatory reactions even years after the performance of a surgical procedure ${ }^{12}$, hence the product could interfere in the uptake of the radiopharmaceutical. In the present study, however, bone wax had no significant effect on the uptake of ${ }^{99 \mathrm{~m}} \mathrm{Tc}$-ceftizoxime, either alone or in association with bacterial inoculum. This finding is in line with expectations since ${ }^{99 \mathrm{~m}}$ Tc-ceftizoxime exhibits high specificity for infectious foci, as has been shown previously ${ }^{8}$. However, the result is of crucial importance since secondary inflammatory responses brought about by surgical trauma or by the presence of bone wax can induce an intense inflammatory response at the surgical site and this could generate a false positive diagnosis of deep wound infection if probed with a radiopharmaceutical with inadequate specificity.

The surgical technique of upper median partial sternotomy was employed in the present study because it provided the best approach for conducting the experiment without entering the pleural cavity and without the necessity of ventilatory support. Previous studies have evaluated sternal healing in rats submitted to total median sternotomy, which is the procedure normally employed in humans ${ }^{13}$. However, application of this procedure would require orotracheal intubation and mechanical ventilation of the experimental animals, thus rendering the experiment far more complex. Furthermore, the border between the mediastinum and the pleural cavity in rats is very thin and, therefore, invasion of the pleura would be practically unavoidable.

The bacterial inoculum $\left(2.5 \times 10^{6} \mathrm{CFU}\right)$ employed in the study was based on a report by Barnea et al..$^{13}$, who estimated that $10^{5}$ to $10^{7} \mathrm{CFU}$ was the lowest amount of inoculum required to produce mediastinitis but with minimum animal mortality. Although macroscopic examination of the surgical wounds of infected animals at the end of the experimental period did not disclose any clinical signs of mediastinitis, histopathological analysis revealed the presence of an intense polymorphonuclear inflammatory process that indicated an acute reaction to infection. The findings reported herein confirm that the experimental model employed was very efficient in inducing subclinical infection of the sternal wound, was highly reproducible and was well tolerated by the experimental animals.

Despite advances in the treatment of mediastinitis, the condition still gives rise to significant mortality among patients submitted to chest surgery. One of the key problems is the difficulty in diagnosing deep wound infection at an early stage, and this generates a delay in the provision of adequate treatment, which invariably involves a further surgical procedure. Patients with suspected mediastinitis typically undergo computed tomography of the thorax and various laboratory tests, but these techniques lack sensitivity and specificity, particularly in the initial phase of the infectious process. In contrast, scintigraphy employing leukocytes labelled with ${ }^{99 \mathrm{~m}} \mathrm{Tc}$-hexamethylpropyleneamine oxime $\left.{ }^{99 \mathrm{~m}} \mathrm{Tc}-\mathrm{HMPAO}\right)$, coupled or not with single photon emission computed tomography (SPECT), delivers high sensitivity and specificity in the diagnosis of mediastinitis following cardiac surgeries ${ }^{14,15}$. However, the preparation of radiolabelled leukocytes requires sophisticated equipment and trained technicians, is timeconsuming (approximately $3 \mathrm{~h}$ ), and introduces extra risk because of the manipulation of potentially contaminated blood.

The use of radiolabelled antibiotics represents a novel approach in the differentiation of infection from aseptic inflammation. Since the antibiotics are bound to or metabolized by bacteria, the amount of radioactivity measured in the ROI is proportional to the number of microorganisms present at the site. Fluoroquinolone antibiotics, which include ciprofloxacin, sparfloxacin and levofloxacin, are the most commonly used scintigraphic markers of infection. However, the results obtained with these antibiotics are contradictory and exhibit low reproducibility ${ }^{8}$. Thus, Larikka et al. ${ }^{16}$ reported that scintigraphic imaging with ${ }^{99 \mathrm{~m}}$ Tc-ciprofloxacin cannot distinguish aseptic processes from osteomyelitis, and suggested that this limitation is due to the pharmacodynamic properties of the antibiotic including low molecular weight (331.3), low degree of interaction with plasma proteins $(20-40 \%)$ and protracted biological half-life $(4.5 \mathrm{~h})$. According to these authors, ciprofloxacin interacts with a variety of elements before combining with the bacteria, and for this reason scintigraphic imaging shows non-specific uptake at 1 to $4 \mathrm{~h}$ after injection. In contrast, ceftizoxime has a half-life of 1.7 $\mathrm{h}$ and is almost totally eliminated within $24 \mathrm{~h}$ after administration, thus the circulating pool diminishes rapidly favouring the specific uptake of the antibiotic at the infected site.

\section{Conclusions}

To the best of our knowledge, the present study represents the first assessment of the use of scintigraphic imaging with ${ }^{99 \mathrm{~m}} \mathrm{Tc}$ ceftizoxime in the diagnosis of deep sternal wound infection in rats. The accuracy of ${ }^{99 \mathrm{~m}} \mathrm{Tc}$-ceftizoxime in differentiating groups of animals that had been contaminated with bacterial inoculum 
(groups SB and SWB) from those that had not (groups S and SW) was amply demonstrated. It is proposed that scintigraphic imaging with ${ }^{99 \mathrm{~m}} \mathrm{Tc}$-ceftizoxime could provide a reliable technique for the prompt diagnosis of initial and/or subclinical cases of mediastinitis making possible early intervention that would serve to reduce morbidity and mortality. ${ }^{99 m}$ Tc-ceftizoxime has the added advantage of being safer and cheaper than other radiopharmaceuticals employed so far.

\section{References}

1. Dalton ML, Connally SR, Sealy WC. Julian's reintroduction of Milton's operation. Ann Thorac Surg. 1992;53:532-3. doi: 10.1016/0003-4975(92)90293-D.

2. El Oakley RM, Wright JE. Postoperative mediastinitis: classification and management. Ann Thorac Surg. 1996;61:1030-6. doi: 10.1016/0003-4975(95)01035-1.

3. Losanoff JE, Richman BW, Jones JW. Disruption and infection of median sternotomy: a comprehensive review. Eur J Cardiothorac Surg. 2002;21:831-9. PMID: 12062271.

4. Graf K, Ott E, Vonberg RP, Kuehn C, Haverich A, Chaberny IF. Economic aspects of deep sternal wound infections. Eur J Cardiothorac Surg. 2010;37:893-6. doi: 10.1016/j.ejcts.2009.10.005.

5. Yamaguchi H, Yamauchi H, Yamada T, Ariyoshi T, Aikawa H, Kato Y. Diagnostic validity of computed tomography for mediastinitis after cardiac surgery. Ann Thorac Cardiovasc Surg. 2001;7:94-8. PMID: 11371278.

6. Bitkover CY, Cederlund K, Aberg B, Vaage J. Computed tomography of the sternum and mediastinum after median sternotomy. Ann Thorac Surg. 1999;68:858-63. PMID: 10509974.

7. Fowler VG, Kaye KS, Simel DL, Cabell CH, McClachlan D, Smith PK, Levin S, Sexton DJ, Reller LB, Corey GR, Oddone EZ. Staphylococcus aureus bacteremia after median sternotomy: clinical utility of blood culture results in the identification of postoperative mediastinitis. Circulation. 2003;108:73-8. PMID: 12821547.

8. Diniz SO, Rezende CM, Serakides R, Ferreira RL, Ribeiro TG, Martin-Comin J, Cardoso VN. Scintigraphic imaging using technetium-99m-labeled ceftizoxime in an experimental model of acute osteomyelitis in rats. Nucl Med Commun. 2008;29:830-6. doi: 10.1097/MNM.0b013e3283000514.

9. Diniz SOF, Ferrari CS, Nelson DL, Martin-Comin J, Cardoso VN. ${ }^{99 m}$ Technetium-ceftizoxime kit preparation. Braz Arch Biol Technol. 2005;48:89-96. doi: 10.1590/S1516-89132005000700014.

10. Palestro CJ, Love C, Tronco GG, Tomas MB. Role of radionuclide imaging in the diagnosis of postoperative infection. Radiographics. 2000;20:1649-60; discussion 60-3. PMID: 11112819.

11. Achneck HE, Sileshi B, Jamiolkowski RM, Albala DM, Shapiro ML, Lawson JH. A comprehensive review of topical hemostatic agents: efficacy and recommendations for use. Ann Surg. 2010;251:217-28. doi: 10.1097/SLA.0b013e3181c3bcca.
12. Sudmann B, Bang G, Sudmann E. Histologically verified bone wax (beeswax) granuloma after median sternotomy in 17 of 18 autopsy cases. Pathology. 2006;38:138-41. PMID: 16581654.

13. Barnea Y, Carmeli Y, Kuzmenko B, Navon-Venezia S. Staphylococcus aureus mediastinitis and sternal osteomyelitis following median sternotomy in a rat model. J Antimicrob Chemother. 2008;62:133943. doi: 10.1093/jac/dkn378.

14. Liberatore M, Fiore V, D'Agostini A, Prosperi D, Iurilli AP, Santini C, Baiocchi P, Galiè M, Di Nucci GD, Sinatra R. Sternal wound infection revisited. Eur J Nucl Med. 2000;27:660-7. PMID: 10901452.

15. Quirce R, Carril JM, Gutiérrez-Mendiguchía C, Serrano J, Rabasa JM, Bernal JM. Assessment of the diagnostic capacity of planar scintigraphy and SPECT with ${ }^{99 \mathrm{~m}} \mathrm{Tc}-\mathrm{HMPAO}-$ labelled leukocytes in superficial and deep sternal infections after median sternotomy. Nucl Med Commun. 2002;23:453-9. PMID: 11973486.

16. Larikka MJ, Ahonen $\mathrm{AK}$, Niemelä $\mathrm{O}$, Junila JA, Hämäläinen $M M$, Britton K, Syrjälä HP. Comparison of ${ }^{99 \mathrm{~m} T c-c i p r o f l o x a c i n,}{ }^{99 \mathrm{~m} T c}$ white blood cell and three-phase bone imaging in the diagnosis of hip prosthesis infections: improved diagnostic accuracy with extended imaging time. Nucl Med Commun. 2002;23:655-61. PMID: 12089488.

\section{Correspondence:}

Paulo Henrique Nogueira Costa

Hospital de Clínicas, UFMG

Avenida Professor Alfredo Balena, 110/5 andar

30130-100 Belo Horizonte - MG Brasil

Tel./Fax: (55 31)3409-9437

phnc@uol.com.br

Received: May 27, 2015

Review: July 24, 2015

Accepted: Aug 28, 2015

Conflict of interest: none

Financial source: none

${ }^{1}$ Research performed at Laboratory of Experimental Surgery, Faculty of Medicine, Universidade Federal de Minas Gerais (UFMG), Belo Horizonte-MG, Brazil. 